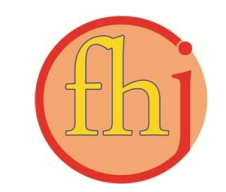

Faletehan Health Journal, 6 (2) (2019) 45-50

www. journal.Ippm-stikesfa.ac.id/ojs/index.php/FHJ

ISSN 2088-673X | e-ISSN 2597-8667

\title{
Determinan Kepemilikan Jamban di Kelurahan Kalanganyar Wilayah Kerja Puskesmas Pancur
}

\author{
Annissa ${ }^{1 *}$, Dhea Pringgandhani Chadhys Putri2 \\ 1,2Program Studi Kesehatan M asyarakat STIKes Faletehan Serang Banten, Indonesia \\ *Corresponding Author: annissa1206@gmail.com
}

\begin{abstract}
Abstrak
Jamban merupakan salah satu fasilitas sanitasi dasar yang dibutuhkan dalam setiap rumah untuk mendukung kesehatan penghuninya sebagai fasilitas pembuang kotoran manusia. Berdasarkan data Puskesmas Pancur yang memiliki jamban sebanyak 367 KK dari total 906 KK. Penelitian ini bertujuan untuk mengetahui faktor-faktor yang berhubungan dengan kepemilikan jamban di Kelurahan Kalanganyar Wilayah kerja Puskesmas Pancur dengan menggunakan desain cross sectional dan jumlah sampel 100 kepala keluarga yang diambil dengan metode simple random sampling. Hasil penelitian diperoleh ada hubungan yang signifikan antara kebiasaan $B A B(p=0,000)$, pendapatan $(p=0,000)$ dengan kepemilikan jamban dan tidak ada hubungan yang signifikan antara pendidikan $(p=1,000)$, peran petugas kesehatan $(p=0,320)$ dengan kepemilikan jamban. Saran untuk penelitian ini adalah perlunya peningkatan kerjasama antar lintas sektor dengan instansi terkait untuk meningkatkan kepemilikan jamban.
\end{abstract}

Kata Kunci: Kebiasaan BAB, Kepemilikan Jamban, Pendapatan, Pendidikan, Peran Petugas

\begin{abstract}
Latrine is one of the basic sanitation facilities needed in every home to support the health of its inhabitants as a human waste disposal facility. Based on data from Puskesmas of Pancur there are 367 heads of families who have latrines from a total of 906 families. The purpose of this research is to know the determinant of the ownership of latrine in Kalanganyar Village Working Area Puskesmas of Pancur 2018. This research design in cross sectional.Population of this research are all household heads / housewives in Kalanganyar Village with a sample of 100 people taken by simple random sampling method. The results suggest that there is a significant relationship between habit of defecation ( $P=0,000)$, income $(P=0,000)$ with latrine ownership, there is no relationship between education $(P=0,000)$ and the role of health workers $(P=0,320)$ with latrine ownership. Suggestion for this research is need improvement cooperation between crosssectoral with related agency.
\end{abstract}

Keywords: Latrine Ownership, Education, Bad Habit, Income, Officer Role Attitudes 


\section{Pendahuluan}

Sosial budaya merupakan salah satu faktor penting untuk meningkatkan derajat kesehatan masyarakat. Budaya masyarakat yang lebih suka membuang air besar (BAB) di sembarangan tempat membuat mereka enggan membuat jamban di rumah masing-masing (Andreas, 2014). Keadaan lingkungan yang tidak memenuhi persyaratan kesehatan dan perilaku masyarakat dapat merugikan masyarakat baik masyarakat perdesaan maupun perkotaan yang disebabkan kurangnya pengetahuan dan kemampuan masyarakat dibidang kesehatan, ekonomi, maupun teknologi. Kondisi lingkungan yang berpengaruh terhadap kesehatan adalah penyediaan air bersih, penyediaan jamban keluarga, kondisi rumah, dan kondisi lingkungan pemukiman (Ady, 2011).

Meningkatkan kesadaran, kemauan, kemampuan hidup sehat bagi setiap orang merupakan tujuan dari pembangunan kesehatan menuju Indonesia sehat 2025. Peningkatan derajat kesehatan masyarakat yang setinggi-tingginya dapat terwujud melalui terciptanya masyarakat, bangsa, dan negara Indonesia yang ditandai oleh penduduknya yang hidup dengan perilaku dan dalam lingkungan sehat, memiliki kemampuan untuk menjangkau pelayanan kesehatan yang bermutu secara adil dan merata (Depkes, 2008).

Kesehatan merupakan hak dasar manusia dan menentukan kualitas Sumber Daya Manusia. Oleh karena itu perlu dipelihara dan ditingkatkan kualitasnya. Derajat kesehatan dipengaruhi oleh lingkungan, perilaku, pelayanan kesehatan dan keturunan. Faktor lingkungan dan faktor perilaku sangat mempengaruhi derajat kesehatan. Faktor lingkungan adalah keadaan pemukiman atau perumahan, tempat kerja, sekolah dan tempat umum, air dan udara bersih, juga teknologi, pendidikan, sosial dan ekonomi. Sedangkan faktor perilaku tergambar dalam kebiasaan sehari-hari seperti pola makan, kebersihan perorangan, gaya hidup, dan perilaku terhadap upaya kesehatan (DepkesRI, 2009).

Kesehatan sangat diidamkan oleh setiap manusia dengan tidak membedakan status sosial maupun usia. Kita hendaknya menyadari bahwa kesehatan adalah sumber dari kesenangan, kenikmatan dan kebahagian. Untuk mempertahankan kesehatan yang baik kita harus mencegah banyaknya ancaman yang akan mengganggu kesehatan kita. Ancaman lain terhadap kesehatan adalah pembuangan kotoran (feces dan urin) yang tidak menurut aturan, seperti buang air besar di sembarang tempat. Buang Air Besar (BAB) di sembarangan tempat itu berbahaya, karena itu akan memudahkan penyebaran penyakit lewat lalat, udara dan air (Chandra, 2007).

Diperkirakan sebesar 1,1 miliar orang atau 17\% penduduk dunia masih $\mathrm{BAB}$ di area terbuka, dari data tersebut sebesar $81 \%$ penduduk yang Buang Air Besar Sembarangan (BABS) terdapat di 10 negara, yaitu India (58\%), Indonesia (12\%), China $(4,5 \%)$, Ethiopia $(4,4 \%)$, Pakistan $(4,3 \%)$, Nigeria (3\%), Sudan (1,5\%), Nepal (1,3\%), Brazil (1,2\%), Niger $(1,25 \%)$ dan Indonesia sebagai Negara kedua terbanyak ditemukan masyarakat buang air besar di area terbuka. Masih terdapat sekitar $12 \%$ penduduk Indonesia yang belum memiliki jamban, dari 2,4 milliar penduduk dunia yang tidak memiliki jamban, dengan rasio tujuh dari sepuluh orang di dunia masih $\mathrm{BAB}$ di tempat terbuka, dimana sebagian besar adalah di sungai (WHO, 2014).

Kepemilikan jamban disetiap rumah sangat dipengaruhi oleh partisipasi seluruh anggota keluarga terutama kepala keluarga. Berdasarkan data yang diperoleh dari Puskesmas Pancur tahun 2018 jumlah KK yang memiliki jamban di 5 Kelurahan pada Kecamatan Taktakan sebanyak $4.439(66.39 \%)$ dari total KK keseluruhan berjumlah 6.686. Diantara kelurahan yang ada di Wilayah Kerja Puskesmas Pancur, Kelurahan Kalanganyar menjadi urutan yang paling rendah kepemilikan jambannya dengan jumlah KK yang memiliki jamban sebanyak 367 (45,88\%) dari jumlah KK keseluruhan 906 yang diperoleh dari data jumlah penduduk Kelurahan Kalanganyar.

Berdasarkan data yang diperoleh dari Kelurahan Kalanganyar, rata-rata pendidikan terakhir yang dimiliki oleh kepala keluarga adalah tingkat Sekolah Dasar (SD) sedangkan rata-rata pekerjaan yang dimiliki oleh kepala keluarga adalah buruh harian lepas dengan pendapatan Rp. 2.000.000 setiap bulan nya. Tingkat pendapatan seseorang untuk memenuhi kebutuhan hidup atau status ekonomi yang baik akan berpengaruh pada fasilitas yang diperoleh. Apabila tingkat pendapatan baik, maka fasilitas kesehatan mereka khususnya didalam rumahnya akan terjamin, misalnya dalam penyediaan jamban keluarga. 
Faletehan Health Journal, 6 (2) (2019) 45-50

www. journal.Ippm-stikesfa.ac.id/ojs/index.php/FHJ

ISSN 2088-673X | 2597-8667

Tingkat pendidikan yang rendah mempengaruhi perilaku masyarakat menjadi tidak baik dalam melakukan Buang Air Besar (BAB), karena masalah tersebut perlu adanya peran petugas kesehatan untuk merubah perilaku tidak baik tersebut (Andreas, 2014). Penelitian ini bertujuan untuk mengetahui faktor-faktor yang berhubungan dengan kepemilikan Jamban di Kelurahan Kalanganyar Wilayah Kerja Puskesmas Pancur Tahun 2018

\section{Metode Penelitian}

Penelitan ini bersifat deskriptif korelasional dengan desain penelitian yang digunakan adalah Cross Sectional yaitu mengukur variabel-variabel dalam penelitian pada waktu yang sama. Penelitian dilakukan di Kelurahan Kalanganyar Wilayah Kerja Puskesmas Pancur pada bulan April sampai dengan Juni Tahun 2018. Variabel independen dalam penelitian ini adalah pendidikan, kebiasaan Buang Air Besar (BAB), pendapatan, dan peran petugas kesehatan. Sedangkan variabel dependen dalam penelitian adalah kepemilikan jamban.

Populasi dalam penelitian adalah seluruh Kepala Keluarga (KK) atau ibu rumah tangga di Kelurahan dengan jumlah 906 Kepala Keluarga (KK). Sampel diambil secara Simpel Random Sampling dengan total sampel adalah $100 \mathrm{KK}$ atau ibu rumah tangga yang diperoleh dengan menggunakan rumus besar sampel minimal.

Pada penelitian pengumpulan data primer dilakukan dengan wawancara terhadap responden dan pengamatan dengan instrumen penelitian berupa kuesioner. Sementara pengumpulan data sekunder dilakukan dengan melihat data dari Puskesmas Pancur dan Kantor Kelurahan Kalanganyar. Proses pengolahan data pada penelitian ini terdiri dari pemeriksaan (editing) data, pemberian kode (coding) data, pemasukan (entry) data, dan pembersihan (cleaning) data. Analisa data dilakukan secara univariat dan bivariat. Analisa univariat dilakukan untuk memperoleh gambaran data mengenai distribusi frekuensi dan proporsi tiap variabel dalam penelitian. Analisa bivariat dilakukan untuk mengetahui apakah ada hubungan yang signifikan antara variabel independen dan dependen dengan menggunakan Uji Kai Kuadrat (Chi Square test) (Nilai $\mathrm{P}<0,05$ ).

\section{Hasil dan Pembahasan}

\section{Gambaran Kepemilikan Jamban terkait karakteristik responden}

Hasil penelitian yang dianalisis secara univariat, pada tabel 1 sebanyak $37,0 \%$ responden yang tidak memiliki jamban, sebanyak 99,0\% responden yang memiliki pendidikan rendah, sebanyak $41,0 \%$ responden yang memiliki kebiasaan BAB tidak baik, sebanyak 59,0\% responden yang memiliki pendapatan rendah, dan sebanyak $11,0 \%$ responden yang menyatakan peran petugas kesehatan kurang baik.

\section{Hubungan karakteristik responden dengan kepemilikan jamban}

Berdasarkan tabel 2, dari 99 responden yang memiliki pendidikan rendah sebanyak $37(37,4 \%)$ responden yang tidak memiliki jamban, dan sebanyak $1(100 \%)$ yang memiliki pendidikan tinggi dan memiki jamban. Dari 41 responden yang memiliki kebiasaaan BAB tidak baik sebanyak 37 $(90,2 \%)$ responden yang tidak memiliki jamban, sedangkan dari 59 responden dengan kebiasaan BAB baik seluruhnya memiliki jamban.

Tabel 1 Distribusi Frekuensi Kepemilikan Jamban, Pendidikan, Kebiasaan BAB, Pendapatan, Peran Petugas Kesehatan

\begin{tabular}{llc}
\hline \multicolumn{1}{c}{ Variabel } & F & \% \\
\hline Kepemilikan Jamban & & \\
$\quad$ Tidak Memiliki & 37 & 37,0 \\
$\quad$ Memiliki & 63 & 63,0 \\
\hline $\begin{array}{l}\text { Pendidikan } \\
\text { Rendah }\end{array}$ & 99 & 99,0 \\
$\quad$ Tinggi & 1 & 1,0 \\
\hline $\begin{array}{l}\text { Kebiasaan BAB } \\
\text { Tidak Baik }\end{array}$ & 41 & 41,0 \\
$\quad$ Baik & 59 & 59,0 \\
\hline $\begin{array}{l}\text { Pendapatan } \\
\text { Rendah } \\
\text { Tinggi }\end{array}$ & 59 & 59,0 \\
Peran Petugas Kesehatan & 41 & 41,0 \\
$\quad$ Kurang baik & 11 & 11,0 \\
$\quad$ Baik & 89 & 89,0 \\
\hline \multicolumn{1}{c}{ Jumlah } & 100 & 100 \\
\hline Sur
\end{tabular}

Sumber : Data Primer, 2018 
Dari 59 responden yang memiliki pendapatan rendah sebanyak $32(54,2 \%)$ responden yang tidak memiliki jamban, sedangkan dari 41 responden yang memiliki pendapatan tinggi sebanyak 5 $(12,2 \%)$ responden yang tidak memiliki jamban. Dari 11 responden yang menyatakan peran petugas kesehatan kurang baik sebanyak $6 \quad(54,5 \%)$ responden yang tidak memiliki jamban, sedangkan dari 89 responden yang menyatakan peran petugas kesehatan baik sebanyak $31(34,8 \%)$ responden yang tidak memiliki jamban.

Hasil analisis bivariat dengan menggunakan uji Chi-square diperoleh secara statistik pada $\alpha 5 \%$ ada hubungan yang signifikan antara kebiasaan $\mathrm{BAB}$ (Nilai $\mathrm{P}=0,000$ ), dan pendapatan (Nilai $\mathrm{P}=0,000)$ dengan kepemilikan jamban di Kelurahan Kalanganyar Wilayah Kerja Puskesmas Pancur Tahun 2018 (Nilai $\mathrm{P}<0,05$ ). Sedangkan variabel pendidikan (Nilai $\mathrm{P}=1,000$ ) dan peran petugas kesehatan (Nilai $\mathrm{P}=0,320$ ) secara statistik pada $\alpha 5 \%$ tidak ada hubungan yang signifikan dengan kepemilikan jamban di Kelurahan Kalanganyar Wilayah Kerja Puskesmas Pancur Tahun 2018 (Nilai P > 0,05).

\section{Pendidikan}

Pada penelitian ini dari dari 99 responden dengan pendidikan rendah sebanyak $37(37,4 \%)$ responden yang tidak memiliki jamban, sedangkan terdapat 1 reponden berpendidikan tinggi dan memiliki jamban. Dari hasil uji analisis bivariat diperoleh tidak ada hubungan antara pendidikan dengan kepemilikan jamban $\mathrm{Hal}$ ini ini tidak sejalan dengan penelitian yang dilakukan oleh Fera Novitri (Novitry, 2017). Menurut Notoatmodjo, Pendidikan adalah upaya persuasi atau pembelajaran kepada masyarakat agar mau melakukan tindakan atau praktek untuk memelihara (mengatasi masalah) dan meningkatkan kesehatannya.

Perubahan atau tindakan pemeliharaan dan peningkatan kesehatan yang dihasilkan oleh pendidikan kesehatan ini didasarkan pengetahuan dan kesadarannya melalui proses pembelajaran, sehingga perilaku tersebut diharapkan akan berlangsung lama dan menetap karena didasari oleh kesadaran. Memegang kelemahan perilaku melalui proses pembelajaran yang pada umumnya memerlukan waktu lama (Notoatmodjo, 2003). Dari penelitian ini dapat dilihat bahwa kepala keluarga di Kelurahan Kalanganyar yang memiliki tingkat pendidikan tamat Sekolah Dasar (SD) yaitu sebanyak $86(86,0 \%)$ responden, sedangkan tidak sekolah atau tidak tamat SD $5(5,0 \%)$ responden, tamat SMP $8(8,0 \%)$ responden, dan tamat Perguruan Tinggi (PT) $1(1,0 \%)$ responden.

Tabel 2. Hubungan Antara Pendidikan, Kebiasaan BAB, Pendapatan, dan Peran Petugas Kesehatan Dengan Kepemilikan Jamban di Kelurahan Kalanganyar Wilayah Kerja Puskesmas Pancur Tahun 2018

\begin{tabular}{|c|c|c|c|c|c|c|}
\hline \multirow{3}{*}{ Variabel } & \multicolumn{4}{|c|}{ Kepemilikan Jamban } & \multirow{3}{*}{ Jumlah } & \multirow{3}{*}{ P value } \\
\hline & \multicolumn{2}{|c|}{ Tidak Memiliki } & \multicolumn{2}{|c|}{ Memiliki } & & \\
\hline & $\mathbf{N}$ & $\%$ & $\mathbf{N}$ & $\%$ & & \\
\hline \multicolumn{7}{|l|}{ Pendidikan } \\
\hline Rendah & 37 & 37,4 & 62 & 62,6 & 99 & 1,000 \\
\hline Tinggi & 0 & 0,0 & 1 & 100 & 1 & \\
\hline \multicolumn{7}{|l|}{ Kebiasaan BAB } \\
\hline Tidak Baik & 37 & 90,2 & 4 & 9,8 & 41 & 0,000 \\
\hline Baik & 0 & 0,0 & 59 & 100 & 59 & \\
\hline \multicolumn{7}{|l|}{ Pendapatan } \\
\hline Rendah & 32 & 54,2 & 27 & 45,8 & 59 & 0,000 \\
\hline Tinggi & 5 & 12,2 & 36 & 87,8 & 41 & \\
\hline \multicolumn{7}{|l|}{ Peran Petugas Kesehatan } \\
\hline Kurang Baik & 6 & 54,5 & 5 & 45,5 & 11 & 0,320 \\
\hline Baik & 31 & 34,8 & 58 & 65,2 & 89 & \\
\hline Jumlah & 37 & 37,0 & 63 & 63,0 & 100 & \\
\hline
\end{tabular}

Sumber : Data Primer, 2018 
Faletehan Health Journal, 6 (2) (2019) 45-50

www. journal.Ippm-stikesfa.ac.id/ojs/index.php/FHJ

ISSN 2088-673X | 2597-8667

Dari hasil penelitian di lapangan, mayoritas pendidikan terakhir responden adalah pendidikan dengan kategori rendah yaitu Sekolah Dasar (SD). Pendidikan yang rendah akan menghambat perkembangan sikap seseorang sehingga berdampak pada perilaku kesehatan. Namun bertolak belakang dengan kenyataan yang ada di lapangan, masyarakat yang memiliki pendidikan rendah justru sebagian besar memiliki jamban. Hal ini dapat terjadi karena adanya kesadaran masyarakat mengenai pentingnya jamban dan peran dari petugas kesehatan setempat yang sudah memberikan penyuluhan maupun memotivasi masyarakat dengan baik.

\section{Kebiasaan BAB}

Pada penelitian ini dari 41 responden dengan kebiasaan BAB tidak baik sebanyak 37 (90,2\%) responden yang tidak memiliki jamban, sedangkan dari 59 responden dengan kebiasaan $\mathrm{BAB}$ baik seluruhnya memiliki jamban. Dari hasil uji analisis bivariat diperoleh ada hubungan antara kebiasaan BAB dengan kepemilikan jamban. Hal ini sesuai dengan penelitian sebelumnya yang menyatakan adanya hubungan antara kebiasaan $\mathrm{BAB}$ terhadap kepemilikan jamban (Darsana, 2012).

Kebiasaan adalah perbuatan manusia yang tetap dilakukan berulang-ulang dalam hal yang sama. Dalam hal ini kebiasaan yang dimaksud adalah kebiasaan dimasyarakat luas yang berlaku bila akan BAB. Kebiasaan tersebut seperti menggunakan jamban keluarga, jamban umum, parit, sungai, dan tempat lainnya untuk BAB (Sobarudin, 2012). Berdasarkan hasil penelitian, mayoritas kebiasaan $\mathrm{BAB}$ responden adalah kebiasaan $\mathrm{BAB}$ dengan kategori baik, artinya responden sudah menggunakan jamban untuk melakukan Buang Air Besar (BAB). Responden yang memiliki kebiasaan baik seluruhnya sudah memiliki jamban dirumahnya.

\section{Pendapatan}

Dari penelitian yang dilakukan pendapatan rendah sebanyak $27(45,8 \%)$ responden yang memiliki jamban, sedangkan dari 41 responden dengan pendapatan tinggi sebanyak $36(87,8 \%)$ responden yang memiliki jamban. Dari hasil analisis bivariat diperoleh ada hubungan antara pendapatan responden dengan kepemilikan jamban. Penelitian ini sejalan dengan penelitian sebelumnya yang menyatakan bahwa adanya hubungan antara pendapatan terhadap kepemilikan jamban (Putri, 2016).

Dalam Kamus Besar Bahasa Indonesia (KBBI) pendapatan adalah hasil kerja (usaha atau sebagainya). Sedangkan dalam kamus manajemen adalah uang yang diterima oleh perorangan, perusahaan, dan organisasi lain dalam bentuk upah, gaji, sewa, bunga, komisi, ongkos, dan laba (Marbun, 2003). Berdasarkan hasil didapatkan bahwa pendapatan yang diperoleh kepala keluarga di Kelurahan Kalanganyar berkisar antara Rp.100.000-Rp.3.500.000. Berdasarkan penelitian yang dilakukan, mayoritas pendapatan responden adalah pendapatan dengan kategori rendah yaitu dibawah rata-rata sebesar Rp. 1.370.000. Rendahnya tingkat kepemilikan jamban erat kaitannya dengan pendapatan keluarga yang berada dibawah rata-rata, sehingga masyarakat tidak memiliki kemampuan untuk membangun jamban sendiri.

\section{Peran Petugas Kesehatan}

Pada penelitian ini dari dari 11 responden yang menyatakan peran petugas kurang baik sebanyak $5(45,5 \%)$ responden yang memiliki jamban, sedangkan dari 89 responden yang menyatakan peran petugas kesehatan baik sebanyak $58(65,2 \%)$ responden yang memiliki jamban. Dari hasil analisa bivariat diperoleh tidak ada hubungan antara peran petugas kesehatan dengan kepemilikan jamban. Responden yang menyatakan peran petugas kesehatan baik tetapi tidak memiliki jamban, hal ini dikarenakan selain dari faktor peran petugas kesehatan, ada faktor lain yang mendukung masih adanya responden yang tidak memiliki jamban yaitu faktor pendapatan yang rendah. Tingkat pendapatan seseorang untuk memenuhi kebutuhan hidup atau status ekonomi yang baik akan berpengaruh terhadap fasilitas yang diperoleh. Apabila tingkat pendapatan baik, maka fasilitas kesehatan mereka khususnya didalam rumahnya akan terjamin, misalnya dalam penyediaan jamban keluarga.

\section{Simpulan}

Berdasarkan penelitian dapat disimpulkan bahwa di Kelurahan Kalanganyar Wilayah Kerja Puskesmas Pancur masih terdapat masyarakat yang tidak memiliki jamban (37\%), berpendidikan 
rendah (99\%), kebiasaan BAB tidak baik (41\%), memiliki pendapatan rendah sebanyak $59 \%$, dan yang menyatakan peran petugas kesehatan kurang baik sebanyak $11 \%$. Terdapat hubungan yang signifikan antara kebiasaan $\mathrm{BAB}(\mathrm{p}=0,000)$ dan pendapatan $(0,000)$ dengan kepemilikan jamban dan tidak ada hubungan yang signifikan antara pendidikan $(\mathrm{p}=1,000)$ dan peran petugas kesehatan $(\mathrm{p}=0,320)$ dengan kepemilikan jamban.

\section{Referensi}

Ady. (2011). Faktor-faktor yang mempengaruhi kepemilikan jamban. studi tentang faktorfaktor yang mempengaruhi kepemilikan jamban.

Andreas, H. (2014). Faktor-Faktor Yang Mempengaruhi Perilaku Keluarga dalam Menggunakan Jamban di Desa Tawin Kecamatan Teluk Kota Ambon. Semarang: Universitas Diponegoro.

Chandra, B. (2007). Pengantar Kesehatan Lingkungan. Jakarta: Buku Kedokteran EGC.

Darsana, N. I. (2012). Faktor- Faktor yang Berhubungan dengan Kepemilikan Jamban Keluarga di Desa Jehem Kecamatan Tembuku Kabupaten Bangli Tahun 2012. Jurnal Kesehatan Lingkungan, vol 4 no 2.

Depkes. (2008). Profil Kesehatan Indonesia 2008. Jakarta: Direktorat Jenderal Bina Kesehatan.
DepkesRI. (2009). Derajat Kesehatan dan Faktornya. Jakarta: Direktorat Jenderal Bina Kesehatan.

Marbun. (2003). Kamus Manajemen. Jakarta: Pustaka Sinar Harapan.

Notoatmodjo, S. (2003). Ilmu Kesehatan Masyarakat. Jakarta: Rineka Cipta.

Novitry. (2017). Determinan Kepemilikan Jamban Sehat di Desa Sukomulyo Martapura Palembang. Jurnal Ilmu Kesehatan Aisyah, 107-116.

Nursalam. (2008). Konsep dan Penerapan Metodologi Penelitian Ilmu Keperawatan. In T. d. Pedoman Skripsi. Jakarta: Salemba Medika.

Nursalam. (2008). Konsep dan Penerapan Metodologi Penelitian Ilmu Keperawatan: Pedoman Skripsi, Tesis dan Instrumen Penelitian. Jakarta: Salemba Medika.

Putri, W. E. (2016). Analisis Faktor dengan Rendahnya Kepemilikan Jamban di Desa Baru Semerah Sitinjau Laut Kabupaten Kerinci. Retrieved Mei 9, 2018, from http://Jurnal syedzasantika.ac.id

Setiadi. (2008). Keperawatan Keluarga. Jakarta: EGC.

Sobarudin. (2012). Retrieved Mei 2018, from http://www.bisosial.com/2012/Kebiasaan

WHO. (2014). Joint Monitoring Program For Water Supply and Sanitation. Ganeva: WHO Press. 